\title{
Preface to Martin Kutrib Festschrift
}

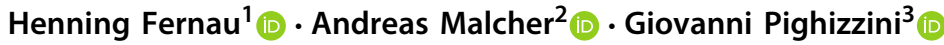

(c) The Author(s), under exclusive licence to Springer-Verlag GmbH Germany, part of Springer Nature 2021

This special issue of Acta Informatica is dedicated to Professor Dr. Martin Kutrib on the occasion of his 60th birthday on the 18th of August 2021.

Martin Kutrib studied informatics at the Technical University of Braunschweig and received his Diploma in 1989, with a thesis written under the supervision of Roland Vollmar. He then worked as graduate assistant at the University of Giessen and obtained in 1993 the Doctorate in Informatics from the University of Giessen. His thesis on Kellererweiterte Polyautomaten (cellular automata augmented with pushdown stores) was supervised by Henner Kröger. In 1999 he received the Habilitation in Informatics again from the University of Giessen. He started his academic career in 1994 as a Visiting Researcher at the University of Siegen and continued as Assistant Professor and Lecturer at the University of Giessen. In 2004 he was appointed as Professor at the University of Giessen.

The scientific work of Martin Kutrib comprises many facets of theoretical computer science such as, for example, cellular automata, descriptional complexity of machines, state complexity of operations, reversible machines, bio-inspired models, and fundamental questions in automata theory and formal languages. His scientific merits are documented by more than 250 peer-reviewed publications amongst them more than 150 conference papers and more than 100 journal papers.

Moreover, he has been member of the program committee of more than fifty workshops and conferences and co-chaired ten of these. Martin Kutrib currently is editor-in-chief of Journal of Automata, Languages and Combinatorics, honorary editor of International Journal of Unconventional Computing, and member of the editorial board of Journal of Cellular Automata and International Journal of Foundations of Computer Science, and he edited twelve special issues in different journals.

\footnotetext{
Henning Fernau

fernau@uni-trier.de

Andreas Malcher

andreas.malcher@informatik.uni-giessen.de

Giovanni Pighizzini

pighizzini@di.unimi.it

1 Universität Trier, Trier, Germany

2 Universität Giessen, Giessen, Germany

3 Università degli studi di Milano, Milan, Italy
} 
Martin Kutrib is a very active member of different computer science organizations to promote the field of automata theory and formal languages and, in particular, the topics of descriptional complexity and cellular automata. Some of his activities are:

- Member of the Working Group 1.2 Descriptional Complexity of the International Federation of Information Processing (IFIP) starting in 2012,

- Chairman of the Working Group 1.2 Descriptional Complexity of IFIP starting in 2018,

- Member of the Working Group 1.5 Cellular Automata and Discrete Complex Systems of IFIP starting in 1999,

- Chairman of the Special Interest Group Automaten und Formale Sprachen of the German Computer Science Society GI (Gesellschaft für Informatik) from 2009 to 2015,

- Co-Initiator and member of the steering committee of the series of workshops on NonClassical Models of Automata and Applications starting in 2009,

- Member of the steering committee of the series of conferences on Descriptional Complexity of Formal Systems starting in 2012; he is chair of the steering committee since 2018,

- Member of the steering committee of the series of conferences on Developments in Language Theory, starting in 2013.

We would like to thank the authors for accepting our invitation and for contributing to this special issue. The list of authors and the topics of their contributions show their relation to Martin Kutrib and his scientific work in the one or the other way. Each contribution has passed the standard reviewing process of the journal.

We would also like to thank all those who helped to produce this special issue, especially the referees for their timely cooperation and Christel Baier and the team of Acta Informatica for their cooperation on this project.

Last but not least, we would like to thank Martin for his friendship and for many stimulating discussions, maybe while taking a cup of coffee in front of a whiteboard, or sometimes with a beer or glass of wine during the dinner.

Dear Martin, we all wish you Happy Birthday and many more conferences and papers to come!

Henning Fernau, Andreas Malcher, and Giovanni Pighizzini

Publisher's Note Springer Nature remains neutral with regard to jurisdictional claims in published maps and institutional affiliations. 